East Tennessee State University

Digital Commons@ East Tennessee State University

ETSU Faculty Works

Faculty Works

$1-1-2014$

\title{
Optimism and Planning for Future Care Needs Among Older Adults
}

\author{
Silvia Sörensen \\ University of Rochester \\ Jameson K. Hirsch \\ University of Rochester, hirsch@etsu.edu \\ Jeffrey M. Lyness \\ University of Rochester
}

Follow this and additional works at: https: / dc.etsu.edu/etsu-works

Part of the Behavior and Behavior Mechanisms Commons, Health Psychology Commons, and the Public Health Commons

\section{Citation Information}

Sörensen, Silvia; Hirsch, Jameson K.; and Lyness, Jeffrey M.. 2014. Optimism and Planning for Future Care Needs Among Older Adults. GeroPsych. Vol.27(1). 5-22. https://doi.org/10.1024/1662-9647/a000099 ISSN: 1662-9647

This Article is brought to you for free and open access by the Faculty Works at Digital Commons @ East Tennessee State University. It has been accepted for inclusion in ETSU Faculty Works by an authorized administrator of Digital Commons @ East Tennessee State University. For more information, please contact digilib@etsu.edu. 


\section{Optimism and Planning for Future Care Needs Among Older Adults}

\section{Copyright Statement}

(C) (C) 2014 Hogrefe Publishing. This document is an author manuscript from PMC. The publisher's final edited version of this article is available at GeroPsych. 
Published in final edited form as:

GeroPsych (Bern). 2014 ; 27(1): 5-22. doi:10.1024/1662-9647/a000099.

\title{
Optimism and Planning for Future Care Needs among Older Adults
}

\author{
Silvia Sörensen ${ }^{1}$, Jameson K. Hirsch ${ }^{1,2}$, and Jeffrey M. Lyness ${ }^{1}$ \\ ${ }^{1}$ Department of Psychiatry, University of Rochester School of Medicine and Dentistry, Rochester, \\ NY, USA \\ ${ }^{2}$ Department of Psychology, East Tennessee State University, Johnson City, TN, USA
}

\begin{abstract}
Aging is associated with an increase in need for assistance. Preparation for future care (PFC) is related to improved coping ability as well as better mental and physical health outcomes among older adults. We examined the association of optimism with components of PFC among older adults. We also explored race differences in the relationship between optimism and PFC. In Study 1 , multiple regression showed that optimism was positively related to concrete planning. In Study 2, optimism was related to gathering information. An exploratory analysis combining the samples yielded a race interaction: For Whites higher optimism, but for Blacks lower optimism was associated with more planning. High optimism may be a barrier to future planning in certain social and cultural contexts.
\end{abstract}

\section{Keywords}

optimism; future care planning; race differences; avoidance; decision making and planning beliefs

\begin{abstract}
Optimism is conceptualized as a general, positive attitude about the future and a tendency to anticipate favorable outcomes to life situations (Scheier \& Carver, 1985). Considered a stable, trait-like personality characteristic, optimism can significantly affect older adults' health and well-being. For older adults, high optimism is related to positive health outcomes including greater likelihood of successful adjustment to and recovery from disease, increased survival, better quality of life, and less difficulty and distress making healthrelated decisions (Achat, Kawachi, Spiro, DeMolles, \& Sparrow, 2000; Kubzansky et al., 2002; Ostir, Markides, Peek, \& Goodwin, 2001; Robinson-Whelen, Kim, MacCallum, \&
\end{abstract}

\footnotetext{
(C) 2014 Hogrefe Publishing

Silvia Sörensen, Department of Psychiatry, University of Rochester School of Medicine and Dentistry, Box PSYCH, 300 Crittenden Blvd, Rochester, NY 14642, USA, silvia_sorensen@urmc.rochester.edu

${ }^{1}$ We use the term "Blacks" in the current article because in our study we included both Caribbean-American and African-American participants, and the literature in this area rarely distinguishes between the two. Blacks would be the overarching term describing racial background. We are aware that the unproven assumption is that racial background is a proxy for cultural norms in the context of this article. Clearly, future research is needed that has been designed to distinguish more precisely between individuals of different cultural backgrounds, both among the White and Black population.
}

Declaration of Conflicts of Interest

The authors declare that no conflicts of interest exist. 
Kiecolt-Glaser, 1997). In contrast, expectations of negative future outcomes, or a pessimistic perspective, have been linked to cognitive avoidance and disengagement from illness or impairment (Duke, Leventhal, Brownlee, \& Leventhal, 2002), as well as being associated with greater functional impairment, a need for more extensive instrumental assistance, and higher levels of perceived stress by those requiring care (Rakowski \& Clark, 1985). One mechanism through which optimism may positively affect late life health is by influencing the appraisal of age-related impairment as something that can be prevented, planned for, and/or managed ("secondary appraisal," (Lazarus, 1991) or "action and personal resource beliefs" (Schwarzer, 1994)), thus facilitating successful adjustment (Chang, 1998).

However, optimism appears to be a double-edged sword. Schwarzer (Schwarzer, 1994) argues that "functional optimism" is indeed linked to the adoption of preventive health behaviors and positive mental and physical outcomes, but that unrealistic or "defensive" optimism may in fact prevent accurate threat appraisal, thus undermining positive health behaviors. Others have found that more pessimistic expectations in later life are associated with positive health outcomes, whereas unrealistic optimism about the future is associated with a higher likelihood of disability and mortality within the following decade (Lang, Weiss, Gerstorf, \& Wagner, 2013).

\section{Preparation for Future Care}

With aging the likelihood of chronic medical illness and functional impairment increases, as does the need to plan for medical or long-term care (Parker \& Thorslund, 2007). Persons aged 65 face an average of 3 years of long-term care, 2 years of care at home, and 1 year in some type of residential care (Spillman, 2012). But how well does the type of care they receive match their preferences? Preparation for future care (PFC) is conceptualized as a set of health behaviors and beliefs (Klein \& Stefanek, 2007), and may be best understood in the context of the proactive coping paradigm (Aspinwall \& Taylor, 1997), which suggests that future-oriented and goal-driven problem-solving efforts as well as a sense of self-efficacy and competence, are associated with improved coping ability and better mental and physical health outcomes (Fiksenbaum, Greenglass, \& Eaton, 2006; Ironson et al., 2005). Older adults who are more planful and future-oriented report greater life satisfaction in later years (Prenda \& Lachman, 2001). Furthermore, future-oriented thinking enhances subsequent health-promotion behaviors, such as exercise (Kahana, Kahana, \& Zhang, 2005). Planning for future care in particular is associated with lower rates and severity of depression and anxiety in later life (Sörensen, Mak, Chapman, Duberstein, \& Lyness, 2012).

PFC occurs in four stages: (1) awareness and anticipation of risk for future care; (2) gathering information about both risk for care and resources to meet care needs; (3) decision making about health and care preferences, such as choosing an assisted living facility; (4) concrete planning of care arrangements, such as putting one's name on a waiting list (Sörensen \& Pinquart, 2000). Seniors who have high levels of awareness of potential care needs without doing much concrete planning report higher levels of worry about the future and depression symptoms. In contrast, older adults who have made concrete plans have higher levels of satisfaction with preparation, less worry, and fewer depression symptoms than individuals with no concrete plans (Pinquart \& Sörensen, 2002b). 
A fifth facet of PFC, (5) avoidance, assesses the reluctance of older adults to engage in the PFC process. Although avoidance is associated with more positive well-being concurrently, avoidance of thoughts about future care needs is associated with greater depression symptom severity after 2 years (Sörensen, Mak, Chapman, Duberstein, \& Lyness, 2012b). Thus the absence of PFC among older adults has serious long-term implications for the wellbeing of older adults.

Important psychological contributors to PFC are beliefs about the usefulness of planning, and expectations about needing or not needing care in the future (Sörensen \& Pinquart, 2000). In addition, personality traits of neuroticism and openness to experience (Sörensen, Duberstein, Chapman, Lyness, \& Pinquart, 2008), and decision style (Sörensen \& Pinquart, 2001a), predict propensity to engage in PFC. In a related line of research, Socioemotional Selectivity Theory suggests that, with a decrease in perceived length of life, older adults tend to focus more on positive thoughts and validating experiences, rather than gathering information and solving current or future problems (Carstensen, Fung, \& Charles, 2003; Carstensen, 2006). Although concepts from SST would be a relevant addition to the current research, they were not measured in the data for the present study.

Important contextual contributors to PFC and health decision making are sex, education, culture, available information about services, and health policy (Sörensen \& Pinquart, 2001a; Sörensen \& Pinquart, 2001b). Specifically, women, persons with higher education, with more knowledge of services (Delgadillo, Sörensen, \& Costner, 2004; Sörensen \& Pinquart, 2001a), and those embedded in more individualistic cultures and societies with less health care are more likely to plan for future care needs (Sörensen \& Pinquart, 2000). Also, African-Americans in Georgia report higher levels of awareness and avoidance, but lower levels of gathering information, concrete planning, and decision making than Whites (Pinquart, Sörensen, \& Davey, 2003).

\section{Optimism and Planning for Future Care}

High optimism may influence the belief that one can manage emerging stressors, but it also may reflect the belief that such stressors will not occur. Thus, individuals with high optimism may avoid and show less concern about health-related information and procedures (Sears, Woodward, \& Twillman, 2007). Compared to those with more moderate levels of optimism, highly optimistic individuals tend to have and retain less factual knowledge about medical risks (Klein \& Zajac, 2009) and to believe that they are at less risk than peers for diseases and poor health outcomes (Radcliffe \& Klein, 2002; Taylor \& Brown, 1988). This may be particularly problematic for older adults, who already tend to rate their health more positively than would be expected based on objective measurements (Benyamini, Idler, Leventhal, \& Leventhal, 2000; Wilcox, Kasl, \& Idler, 1996). An older adult with very high optimism may be prone to idealistic beliefs that the aging process can be prevented by lifestyle changes and medical interventions and conclude that planning for actual future care needs is not necessary (Walz \& Mitchell, 2007). Thus, high optimism may be comparable to what Schwarzer called "defensive optimism" (Schwarzer, 1994) and represent a risk factor for poor health and mental health outcomes in the context of aging. 
Although preparing for future care needs has become somewhat of an expectable developmental task of later life, few older adults actually engage in such planning (Sörensen \& Pinquart, 2000). In the U.S., older adults rarely respond favorably to policy-driven opportunities to engage in decision making about future care preferences (Administration on Aging, 2009; McCay, Long Term Care Group Inc., \& LifePlans Inc., 2006). In summary, if high optimism reflects unrealistic expectations of disease-free aging, reluctance to engage in PFC would be exacerbated for older adults with high optimism. No published data directly examine the association of optimism with future care planning among older adults.

\section{Race, Preparation for Future Care, and Optimism}

The association of optimism with future care planning may be affected by race and cultural differences. The sociocultural values of diverse groups do not always concur with the Eurocentric values underlying the idea of advance directives and future care planning (Ersek, Kagawa-Singer, Barnes, Blackhall, \& Koenig, 1998). For example, filial responsibility norms among African-Americans suggest that care for frail older adults is the responsibility of family members (Jones, Lee, \& Zhang, 2011), thus limiting care planning activities that take into account other options. Also, high filial obligation may not translate into appropriate planning for the older adult, such as when older adults falsely assume that their family caregivers are aware of their needs. This may be a partial explanation for a finding in a cross-national study which showed that high filial norms are related to lower life satisfaction among elders (Lowenstein, Katz, \& GurYaish, 2007). Cultural differences in social support systems and resources may also play a role in the process of planning and the types of plans made. Some older adults may feel obliged to plan because they do not want toburden their adult children with care decisions and responsibilities, whereas others find reliance on family completely normal. Although filial obligation has been studied extensively, subjective norms to engage in planning for family or nonfamily care have not been measured to date.

In addition, consideration of the future needs for care - and where this care might be obtained - may be affected by barriers similar to those that influence health care access (Escarce, Epstein, Colby, \& Schwartz, 1993; Lillie-Blanton, Brodie, Rowland, Altman, \& McIntosh, 2000) and end-of-life care for nondominant cultural groups. These include feelings of medical mistrust, lack of diversity among health care staff, limited knowledge of medical terminology and confusion about future care needs, poor patient-physician communication, and cultural differences in beliefs about aging and death (Con, 2008; Jenkins, Lapelle, Zapka, \& Kurent, 2005; Matsumura et al., 2002). For example, some research suggests that Blacks ${ }^{1}$ may be concerned about negligent treatment by medical personnel, as a result of historical segregation and oppression (Con, 2008; Crawley et al., 2000). Decreased interest in planning for future medical decisions among Blacks may be due in part to a fear that they will receive inadequate assistance (Crawley et al., 2000; Daaleman \& VandeCreek, 2000). Religiosity and spirituality as well as family and community (rather than physicians) play an important role in the aging and decision-making process for many non-Whites(Con, 2008). Also, because dispositional optimism has been associated with greater perceived benefits of health screening and fewer perceived barriers to treatment among older African-American females (Jones, O'Connell, Gound, Heller, \& 
Forehand, 2004), future expectancies may have a differential effect for Blacks and Whites. Thus, one might expect Blacks to have lower levels of PFC, consistent with their reluctance to engage in advance care and life support planning (McKinley, Evans, \& Danis, 1996; Phipps et al., 2003).

The investigation of cultural factors and future planning has focused primarily on topic of advance directives, which is only one part of the spectrum of planning for the future. We know of no published data that directly examine the interrelationship of ethnicity and optimism as they influence preparation for future care focusing on potential decades of need for assistance, not just the end of life. The rare studies that do address similar topics are inconclusive. For example, a laboratory study showed higher levels of pessimism, more inhibited-passive coping, and reduced cardiovascular response to stressors for Blacks than for Whites (Saab et al., 1997) - but dispositional optimism has also been related to greater perceived benefit of health screening and fewer perceived barriers to treatment among older African-American women (Jones etal., 2004). Pinquart and colleagues (2003) found that African-Americans had different patterns of PFC prevalence than Whites, but few dispositional variables were investigated in this context. Therefore, investigating the relationship of optimism to PFC remains exploratory.

In the current paper we describe secondary data analyses from two studies conducted in 2001-2006, testing several hypotheses regarding the relationship of optimism to different aspects of preparation for future care among community-dwelling older adults. In addition, because the sample in Study 2 had a large percentage of Black participants, we added an exploratory analysis to attempt to understand sample and potential race differences in the relationship between optimism and five PFC subscales: Awareness, Gathering Information, Decision Making, Concrete Planning, and Avoidance (see Methods for details).

\section{Study 1}

We hypothesized (H1a-Hf) that higher optimism would be associated with a pattern of planning for future care needs marked by (a) greater belief in the usefulness of planning but also a (b) greater avoidance of future care planning. We also hypothesized that higher levels of optimism would be associated with (c) less awareness of future care needs, (d) less gathering information, (e) less decision making, and (f) less concrete planning.

\section{Methods}

Participants-In the first study we used cross-sectional data from a sample of older adults recruited from primary care settings, including private internal medicine practices and hospital-affiliated clinics in the greater Rochester (New York) region, during the years 2001 to 2006 and as part of a larger observational study described elsewhere (Travis, Lyness, Shields, King, \& Cox, 2004). Practice physicians provided permission to recruit, a letter of support to use during recruitment, and access to consenting participants' medical files. Office staff identified older patients, who were approached in the waiting room and invited to participate by study staff. The study attempted to recruit all patients aged 65 years and older who presented for care on selected days and were capable of giving consent. Reason 
for visiting the physician was not assessed, but all patients over 65, whether they were there for a routine annual exam or for a specific problem, were included.

More than one third of potential participants consented to participate, a rate consistent with previous work in primary care settings using intensive assessment methodologies (Coyne, Fechner-Bates, \& Schwenk, 1994). Study staff interviewed individuals in their homes and asked them to complete and mail back several questionnaires, including the PFC and optimism measures. Because items assessing optimism were added later and not all participants agreed to fill out additional surveys, 64 (9\%) participants had complete data. This subsample had a mean age of $74.13(S D=5.22)$, a mean education level of 15.3 years ( $S D=1.77$ ), and was $97 \%$ White. (See Table 1 for other demographic characteristics.) The subsample with optimism data did not differ significantly from the overall sample in health (Cumulative Illness Rating Scale, CIRS score). With a mean CIRS score of 10.1, they were slightly healthier than a comparable primary care patients (Fortin, Bravo, Hudon, Vanasse, \& Lapointe, 2005), whose mean CIRS (including the psychiatric systems omitted from our CIRS version) was about 13, indicating disease in at least four or five organ systems (Fortin et al., 2005).

\section{Measures}

Demographics-We asked for education in years, self-identified racial categories, marital status, and income. Means and standard deviations for demographics and study variables are shown in Table 1.

Preparation for Future Care-We used the short form of the Preparation for Future Care Needs measure (PFCN) (Sörensen \& Pinquart, 2001a). The PFCN short form has 15 items and has demonstrated good factor separation and internal consistency $(\alpha=.72-.82)$ in large samples of older adults, and invariant factors across race and administration method (self-administered vs. interview). The subscales are Awareness of Future Care Needs (example item: "The thought that I may need help or care in the future comes up a lot for me"), Gathering Information ("I have compared different options for obtaining help or care in the future"), Decision Making ("I have compared different options of obtaining help or care in the future and have decided which would work for me and which would not"), Concrete Planning ("I have explained to someone close to me what my care preferences are"), and Avoidance ("I try not to think about things like future loss of independence."). In the current sample, Cronbach's as are .74 for Avoidance, .65 for Awareness, .76 for Gathering Information, .75 for Decision Making, and .52 for Concrete Planning, with three items for each subscale. Responses were made using a 5-point Likert scale, and analyses were conducted with the mean across subscale items, allowing for mean imputation from other subscale items from the same subjects, when fewer than $33 \%$ of responses were missing.

Attitudinal Barriers to Planning-Two scales measuring beliefs about the usefulness of planning and the expectation of no future care need (Sörensen \& Pinquart, 2001a). The Belief that Planning is Not Useful scale is a 7-item, 5-level scale rated on a Likert scale ranging from $1=$ disagree completely to $5=$ agree completely. Example item: "It is 
impossible to plan for future care-you must take life one day at a time." Cronbach's $a=.92$ in Sample 1.

The Expectations for No Care measure is a 5-item survey also scored on a Likert scale $(1=$ disagree completely to $5=$ agree completely); sample item: "I don't think I will ever be ill long enough to require care" (primary care sample Cronbach's $a=.76$ ).

Optimism-Using the Life Orientation Test - Revised (LOT-R) (Scheier, Carver, \& \& Bridges, 1994), we assessed trait-like optimism and pessimism via general, dispositional outcome expectancies of the respondent. The LOT-R has six statements (three positively worded, three negatively worded), and participants indicate strength of agreement with each statement using a 5 -point scale $(0=$ strongly disagree to $4=$ strongly agree $)$, with a possible range of scores from 0 to 24 . Examples of items include: "In uncertain times, I usually expect the best"; "If something can go wrong for me, it will"; and "I'm always optimistic about my future." Negatively worded items are reverse scored, and all items are summed to create an overall score. Higher scores indicate increased optimism. The LOT-R shows acceptable re-test reliability (.79 over a 4-month interval) and internal consistency $(\alpha=.78)$ (Scheier et al., 1994); it is negatively associated with depression and hopelessness, and positively associated with improved physical and psychological well-being, in visionimpaired older adults (Brody et al., 2002). Cronbach's a in the current sample was .67.

Functional Status was assessed with a 14-item measure, combining items from the Physical Self Maintenance Scale (PSMS; 8 items) and the Instrumental Activities of Daily Living (IADL; 6 items) scale (Lawton \& Brody, 1969). The interviewer asked whether the subject is able to use the telephone, shop, do housekeeping, prepare food, take medications, do laundry, travel independently, and handle finances. Options ranged from 0 (indicating the individual can complete this activity independently), to 4 (indicating that the individual cannot do this activity at all) for both scales; Cronbach's a for the current sample was .91, and a $z$-score was calculated for use in analyses.

Medical Burden measures participants' health. It was assessed using the Cumulative Illness Rating Scale (CIRS) (Linn, Linn, \& Gurel, 1968). Completed by a physician using information from a subject interview and a review of the medical records, the CIRS quantifies the pathology in 13 organ systems, and has well-established validity (Royall, Cabello, \& Polk, 1998). CIRS scores derived from reviews of physical examination findings in medical charts are highly correlated with CIRS scores derived from post-mortem autopsy performed by a pathologist/medical examiner (Conwell, Forbes, Cox, \& Caine, 1993). In the current study, scores ranged from $5-18$, with a mean of $10.11(S D=3.055)$ out of a maximum of 39, indicating a relatively healthy sample; a $z$-score was calculated for use in analyses.

\section{Statistical Analyses}

Pearson and point-biserial correlations were used to assess bivariate relationships, and to assess for multicollinearity; all variables were retained, as no associations reached unacceptable cutoffs for multicollinearity $(r>.80)$ (Tabachnick \& Fidell, 2001). 
Although the bivariate analyses showed moderate inter-correlations of the PFC variables, ranging from .13 to .50 , we decided not to run multiple regression with this sample, because of its small size and low likelihood of detecting significant effects. Rather, individual linear regression analyses were conducted separately for six dependent variables: five PFC subscales and the belief that planning is not useful. Optimism was the independent variable of interest in all analyses. We covaried age, sex, education, limitations in activities of daily living, number of medical conditions and the expectation that no care will be needed. We did not control for race, since the sample was predominantly White, nor did we covary income because this item received nonresponses in $25 \%$ of cases.

\section{Results of Study 1}

Bivariate analyses (Table 2) did not support any of our initial hypotheses, except H1c. In Study 1, optimism was associated only with lower age, more income, fewer ADL limitations, fewer medical conditions, and less awareness of future care needs. Broken down by PFC subscales, Awareness of Future Care Needs was associated with less avoidance, and surprisingly, less expectations of needing future care, as well as age, education, and income. More Avoidance was also related to the expectation that no care will be needed and the belief that planning is not useful. Gathering Information was endorsed more by women, people with more ADL limitations, and those with less avoidance. Decision Making was most endorsed by individuals with more ADL limitations and more medical conditions as well as those who had engaged in more concrete planning. Concrete Planning was related to more ADL limitations as well as more awareness, gathering information, and decision making. Beliefs that planning is not useful and expectations for no care were significantly and positively correlated. Also, Blacks (despite their very small numbers in this sample), people of higher age, lower education, and lower income were more likely to endorse negative beliefs about care planning. The expectation of not needing care in the future was related to higher age and being Black. Results related to race were based on a very small number of Black subjects, however. Because of the pattern of correlations, beliefs were used as a dependent variable in the subsequent regressions, whereas expectations were used as a covariate.

\section{Multiple Regression}

Beliefs that Planning is Useless (Negative Planning Beliefs)-Inconsistent with H1a, optimism was not related to negative planning beliefs. However, higher education predicted less and expectations of no care predicted more negative planning beliefs. The overall model predicted $46 \%$ of the variance in negative planning beliefs (see Table 3 ).

Avoidance-Inconsistent with $\mathrm{H} 1 \mathrm{~b}$, optimism was not related to avoidance. Expectations of no care were related to more avoidance. The final variance explained in avoidance was non-significant at $10 \%$.

Awareness-Inconsistent with H1c, the sole significant predictor of awareness was expectations for no future care needs. Optimism was not associated with awareness and added only $2 \%$ to the variance explained. The overall model reached significance, predicting $24 \%$ of the variance in Awareness. 
Gathering Information-Optimism was not significantly related to gathering information (inconsistent with H1d), though it trended in the same direction $(p<.10)$. Both sex and awareness showed significant relationships to gathering information. Men were less likely to gather information, whereas individuals more aware of future care needs were also more likely to engage in information-gathering. The final variance explained by the model (40\%) was significant.

Decision Making-Inconsistent with H1e, optimism was not significantly related to decision making, and the full model showed no other individual significant predictor, except sex: Women were more likely to report having made decisions (Table 3 ). The final $R^{2}$ was not significant and explained only $21 \%$ of the variance. In exploratory analyses, we added gathering information as a predictor of decision making; without optimism (Model 1), gathering information was a significant predictor $(\beta=.37, S E=.14, p<.01)$, but it did not remain significant after adding optimism. However, this analysis did yield a significant $R^{2}$ of .30 .

Concrete Planning-Both awareness and optimism were significantly and positively associated with concrete planning (consistent with H1f). Furthermore, optimism added a significant change in the variance explained (6\%), to a total of $26 \%$.

\section{Summary of Study 1}

Analysis of this small, homogeneous sample revealed no evidence that optimism was related to (H1a) greater belief in the usefulness of planning or (H1b) greater avoidance of future care planning. In bivariate, but not multivariate, analyses we found that optimism was associated with (H1c) less awareness. Optimism was also not associated with (H1d) gathering information and (H1e) decision making. In multivariate analyses, optimism was significantly related to (H1f) concrete planning, however.

Thus, our initial conclusion was that optimism has limited value in predicting PFC and is likely only related to PFC at the most concrete, active level of actual plan development (e.g., communicating with others, putting one's name on a mailing list). However, Study 1 was limited in several respects. First, it was relatively small $(N=67)$. An effect size analysis revealed that only effects larger than .09 would be significant. Many of our effect sizes could have been too small to be detected. Second, because this was a secondary analysis of existing data, only two participants were non-White, too few to explore race differences.

\section{Study 2}

Thus, we conducted a second study with a more diverse secondary data set with the same hypotheses and analyses as above. We developed additional hypotheses for older adults based on existing studies that allow inference about race-specific coping styles. For example, Blacks report lower levels of optimism, use a more inhibited-passive coping style, and have a less pronounced cardiovascular response when exposed to stressors than White counterparts (Saab et al., 1997), whereas in a comparison of Black and White female breastcancer patients, Blacks report being less fatalistic, having less denial or wishful thinking, and using less passive coping than Whites. These results suggest that Blacks may have a 
more realistic long-term perspective, which may facilitate active coping (Soler-Vila, Kasl, \& Jones, 2003). Hypothesis $2 \mathrm{a}$ was, therefore, that Black participants would report lower levels of optimism.

With regard to PFC, recent studies of ethnic differences in health care decision making suggest that lack of trust in the health care system, lack of diversity among health care staff, limited knowledge of medical terminology, poor patient-physician communication, and cultural differences in beliefs about aging and death may present potential barriers to future care planning among several non-White ethnic groups. Familial, religious and spiritual factors may play a larger role in the decision making process for non-Whites than medical considerations (Con, 2008). Compared to Whites, Blacks may feel that their needs will be met more by the community or church, or by trusted family members, possibly leading them to postpone future care planning. In addition, previous research suggests that Blacks had lower levels of decision making and concrete planning (Pinquart, Sörensen, \& Davey, 2003). Hypotheses $2 \mathrm{~b}$ stated, therefore, that because African-Americans experience more barriers in the health system, and may have less familiarity with services, Blacks would report lower levels of planning for future care for all subscales except awareness.

\section{Methods}

Participants-Community-dwelling adults aged 59 and older were recruited through community talks at senior centers and places of worship, newspaper advertisements, health fairs, and by posting flyers in prominent places in urban and rural Western New York between February 2003 and December 2006. Because the optimism questionnaire was added later in the data-collection process, complete data were available from 130 subjects (30\%). Ages in this subsample ranged from 59-89 (mean age 71.4, $S D=7.85$ ), with a mean education level of 11.5 years (median $=12, S D=3.58$ ). We named this group the "community sample." Their characteristics are depicted in Table 1. These participants were quite healthy: Out of 23 possible disease burden points, they had an average of 3.33. In comparison, in a study of adults in senior housing complexes, participants had sample had a mean of 3.87 ( $S D=2.31$ ) out of a possible 16 common medical conditions (e.g., diabetes, hypertension; Lachman et al., 1998)). We had good representations of Black and White respondents, but very few other ethnicities, so we used only the data from Black and White respondents. Two biracial respondents were classified as Black. Optimism and PFC were assessed as part of a larger battery administered face-to-face in two 90-minute in-home interviews.

\section{Measures}

Demographics-The same measures as in Study 1 were used.

Preparation for Future Care Needs-The same measure as in Study 1 was used. Cronbach's as for this sample were: .66 for Avoidance; .61 for Awareness; .79 for Gathering Information; .63 for Decision Making; and, .66 for Concrete Planning. 
Attitudinal Barriers to Planning-The same measure as in Study 1 was used: Belief that Planning Is Not Useful (Cronbach's $\alpha=.81$ ) and the Expectations for No Care measure (Cronbach's $a=.61)$.

Optimism-The LOT-R as described for Study 1; Cronbach's a = .52.

Functional Status-In the community sample, a 13-item scale combining items from the modified Physical Self Maintenance Scale (PSMS) and the Instrumental Activities of Daily Living (IADL) scale was used (Lawton \& Brody, 1969). The interviewer asked whether the subject is able to use the telephone, shop, do housekeeping, prepare food, take medications, do laundry, travel independently, and handle finances. Answer options ranged from $1=$ need no help, to $3=$ cannot do this at all. a was .855. A $z$-score was calculated for use in analyses.

Medical Burden measures participants' health. It was assessed with a count of medical conditions diagnosed in the last year or diagnosed before that with lasting effects, including diabetes, orthopedic issues, heart disease, lung disease, etc. The number of conditions was summed, with a maximum of 23 possible. A $z$-score was calculated for use in analyses.

\section{Results of Study 2}

Bivariate Analyses-The belief in the uselessness of planning was associated with lower income, lower education, and being Black, but - contrary to H1a - not with optimism. Optimism was not related to awareness, avoidance, or decision making, contrary to our hypotheses. Awareness was associated with lower income and education, being Black, and, surprisingly, expecting that no care will be required in the future. Avoidance was related to race, with Blacks being more likely to avoid thoughts about care than Whites. It was also related to the belief that planning is not useful and the expectation that care will not be needed in the future. Higher optimism was, however, associated with less gathering information and less concrete planning, as well as lower age and fewer functional limitations. Gathering Information was related to more functional limitations, but to no other sociodemographic variables. It was, however, also related to more awareness and, surprisingly, the belief that future care will not be needed. Decision making was associated with none of the sociodemographic variables, and, in contrast to the primary care sample, not with functional limitations or medical burden. Consistent with PFC theory, it was related to awareness and gathering information, but also with the belief that care will not be needed. Concrete planning, similarly, was associated with gathering information and decision making, and with the belief that care will not be needed. Also, older participants were more likely to report having made concrete plans. The expectation that no future care will be needed was more pronounced among Black than White participants.

\section{Multiple Linear Regression}

Analyses were conducted separately for the six dependent variables: five PFC subscales and the belief that planning is not useful. Optimism was the independent variable of interest in all analyses. We covaried age, sex, education, race, limitations in activities of daily living, 
number of medical conditions and the expectation that no care will be needed. We did not covary income because this item received nonresponses in $27 \%$ of cases.

Beliefs and Attitudes About Planning-Contrary to H1a, optimism was not related to negative beliefs about planning, but more education was. Race and ADL limitations had a positive association with negative planning beliefs, with African-Americans and more impaired individuals endorsing more negative planning beliefs. The variance of planning beliefs was explained at $37 \%, R^{2}$ was significant.

Avoidance-Optimism was not related to avoidance, inconsistent with H1b. Significant predictors of avoidance included sex (men were more likely to avoid) and race (Blacks were more likely to avoid). The final variance explained was significant, but only $19 \%$.

Awareness-Contrary to H1c, optimism was not associated with awareness, but greater awareness was predicted by expectations of no care needs, paradoxically. However, as shown in Table 4, the overall model did not reach significance. The model explained $14 \%$ of the variance of awareness.

Gathering Information-Consistent with $\mathrm{H} 1 \mathrm{~d}$, greater optimism significantly predicted less gathering information, even after controlling for expectations for no care and awareness, which also emerged as significant positive predictors and for demographic/health variables, which were nonsignificant. The final variance explained was $39 \%$ and the $R^{2}$ was significant.

Decision Making-Contrary to H1e, Awareness alone was a significant predictor of decision making. Neither demographic or other control variables, nor optimism, were related to decision making, although the final variance explained (22\%) was significant.

Concrete Planning-Optimism was unrelated to concrete planning (contrary to H1f), but age and ADL limitations were associated with this active PFC variable. The final model explained $21 \%$ of the variance in concrete planning and the final $R^{2}$ was significant.

\section{Summary of Study 1 and 2 Results}

Although a number of associations were significant at the bivariate level, after controlling for potential confounds in multivariate analyses, we found evidence that optimism was related only to less gathering information (H1d) in Sample 2, and more concrete planning (H1f) in Sample 1, suggesting that greater optimism may vary in how it influences aspects of future care planning across different samples. Contrary to our hypotheses, optimism was not directly related to decision making or awareness in either sample. These findings contradict the notion that optimism is unequivocally related to better health behaviors and outcomes for older adults (Ferreira \& Sherman, 2007; Smith, Young, \& Lee, 2004).

Focusing primarily on the multiple regressions, the different patterns of associations in the two samples are notable. For example, negative beliefs about planning were related to expectations that no future care will be needed for the primary care, but not the community sample. In bivariate analyses these beliefs were related to higher avoidance in both samples. 
The expectation that no future care will be needed was positively related to avoidance for the primary care sample, but not the community sample. Furthermore its associations were positive with awareness and gathering information in the community sample, but negative or nonsignificant (respectively) in the primary care sample.

The association of no care expectations to decision making and concrete planning was negligible in both samples. However, PFC (concrete planning) was more influenced by functional limitations in the community than in the primary care sample. Also, despite higher education and income among the primary care participants, levels of concrete planning and decision making were higher in the community sample, and optimism lower.

Our conclusion from these studies was that optimism may play a role in future planning, but that this may be sample-specific. However, which sample characteristics may be contributing to these differences was not yet uncovered.

\section{Exploratory Analyses}

For this reason we proceeded to explore potential reasons for the sample-based differences. Given the potential confound of sample and race in these two studies, and that the samples were significantly different with respect to several other sociodemographic variables, we did not initially combine samples. However, since the only way to disentangle the effects of race and sample is to conduct joint analyses, we present this exploratory approach here.

With the larger combined sample we were able to perform multivariate analyses. We sought to establish whether race would moderate the effects of optimism on planning for future care needs, such that optimism would have a stronger effect on planning for future care for Blacks. Consistent with the sample differences, compared by $t$-tests to Whites, Blacks reported more negative beliefs about usefulness of planning $(p=.001)$, less income $(p<$. $001)$, and less education $(p<.001)$, as well as more avoidance $(p<.01)$, more awareness $(p$ $<.001)$, more gathering information $(p<.01)$, more decision making $(p<.001)$, and more concrete planning $(p<.05)$. In order to control for predictors in which the samples and race groups differed, we included sample and race as dichotomous predictors, age, education, functional limitations, and medical burden as continuous predictors, and expectations for no care and beliefs about the usefulness of planning as additional controls. Optimism was entered after these controls. Lastly, the design included race-by-optimism and sample-byoptimism interaction terms.

Results in Table 5 show that there was a significant multivariate effect for functional limitations, the belief that planning is not useful, and for sample, but not for race, age, gender, care expectations, medical burden, or optimism alone. The race-by-optimism interaction was significant and disordinal, but the sample-by-optimism interaction was not. (We also ran a model including income, but because a large subgroup did not report their income and the results were equivalent to those without income, we do not report this here.)

The tests of between-subjects effects, which test the relationship of predictors to individual PFC subscales, showed that "sample" was related to awareness $(F=15.87, d f=1, p<.001)$, gathering information $(F=7.60, d f=1, p<.01)$, and concrete planning $(F=9.52, d f=1, p$ 
$<.01$ ), despite the inclusion of race and other potential covariates in the equation. The primary care sample (PCS) had lower awareness scores than the community sample (CS, estimated mean for $\mathrm{PCS}=2.93$, mean for $\mathrm{CS}=3.80$ ), lower gathering information scores (estimated mean for PCS $=2.59$, mean for $\mathrm{CS}=3.34$ ), and lower concrete planning scores $(\mathrm{PCS}=2.43, \mathrm{CS}=3.23)$.

Similar to the community sample, in the combined sample functional limitations were primarily and significantly related to concrete planning $(F=10.59, d f=1, p<.001, \beta=.32$, $S E=.10)$ with greater ADL limitations predicting more concrete planning. Associations with the other subscales were not significant. More negative planning beliefs were related to greater avoidance $(F=12.06, d f=1, p<.001, \beta=.30, S E=.01)$, but none of the other PFC subscales. The effects for future care expectations were no longer significant in the combined sample, presumably because they were in opposite directions for the two samples.

The significant race-by-optimism interaction effect in the omnibus test suggested that the effect of optimism, while not a significant independent predictor for the combined sample, may have been moderated by race. The effect was primarily due to the effect on concrete planning $(F=7.84, d f=1, p<.01)$, the other between-subjects effects were not significant. Plotting the interaction (Figure 1) shows that, for Blacks, optimism was negatively associated with concrete planning, whereas for Whites the association was very slightly positive.

\section{Discussion}

Several lines of evidence suggest that PFC and extent of future orientation has public health relevance because planning for circumstances in late life, long-term care, and end-of-life care increases the ability of older adults to make informed choices about long-term care options - and it protects their emotional well-being (Aspinwall, 1997; Caron, Ducharme, \& Griffith, 2006; Congdon \& Magilvy, 2004; Forbes \& Hoffart, 1998; Howlett, Kees, \& Kemp, 2008; Liu \& Tinker, 2001; Maloney, Finn, Bloom, \& Andresen, 1996; Pinquart \& Sörensen, 2002b; Sörensen, Mak, Chapman, Duberstein, \& Lyness, 2012a; Travis \& McAuley, 1998). Similarly, optimism has been linked to positive health outcomes (Rasmussen, Scheier, \& Greenhouse, 2009; Rasmussen, Wrosch, Scheier, \& Carver, 2006), though the effects of unrealistic optimism on health behaviors are often negative (Barnoy, Bar-Tal, \& Treister, 2003; Miles \& Scaife, 2003), potentially placing individuals at risk for negative health outcomes. To our knowledge, this is the first study focusing on the relationship of optimism to PFC.

We hypothesized that higher optimism would be related to (a) greater belief in the usefulness of planning but also a (b) greater expectation that care will not be needed, and (c) greater avoidance of future care planning. Both in bivariate analyses, and after controlling for potential confounds, we did not find evidence for these hypotheses in either sample. The analyses also showed some counterintuitive results, differing across the samples. For example, awareness of future care needs and gathering information were associated with the expectation that no care will be needed in the future in the community sample. This may be related to greater (unmeasured) filial responsibility beliefs and support arrangements among this primarily Black, low-income group, particularly if "needing help" was interpreted as 
needing formal rather than informal assistance. Future research on the interpretation of these items by different cultural groups is needed to better understand these responses. The persistent differences in patterns of associations between samples may be related to preexisting differences between the samples, for example, cultural characteristics related to race differences, age differences, and differences in income and education.

We also hypothesized that higher levels of optimism would be associated with (d) less awareness of future care needs, (e) less gathering information, (f) less decision making, and (g) less concrete planning. In multivariate regressions with separate samples, optimism was related negatively to gathering information in the community sample and positively to concrete planning in the primary care sample, suggesting that being more optimistic inhibits future care planning activities in one sample, but not the other. Contrary to our hypotheses, optimism was not related to decision making in either sample. Thus, our initial conclusion was that optimism has circumscribed value in predicting PFC, tempered by the fact that subsamples may differ in the role that optimism may play in their future planning.

The exploratory analysis combining the two samples was conducted to better understand the sample differences. It accounted for both sample and race effects as well as potential confounders. Results suggested that sample was key in predicting the combined PFC outcomes, regardless of various and race-associated covariates. Specifically, the community sample reported higher levels of awareness, gathering information, and concrete planning. Although race was not an independent predictor, a disordinal interaction between race and optimism indicated that optimism operated differently upon PFC for Blacks than Whites, even after controlling for sample membership. The driving force in this interaction was the effect on concrete planning.

Consistent with previous studies, with primarily White samples, higher optimism was linked to more concrete planning. In many studies, optimists tend to employ more problem-focused coping strategies and more effective ways of emotion regulation (Taylor \& Armor, 1996) as well as greater self-efficacy (Karademas, 2006), all of which contribute to better functioning. In order to formulate a positive appraisal of the future, White older adults may rely on a sense of personal efficacy, or a positive evaluation of the propensity of the social context to provide needed support. This may be quite realistic, given their income and education.

In contrast, for Black participants, higher optimism was associated with less concrete planning. Blacks did not have higher levels of optimism overall: They reported more negative beliefs about planning. Given the income and education differences between Blacks and Whites in our sample, it is possible that lower optimism among Blacks reflects a more realistic assessment for individuals with greater financial constraints and possibly higher levels of overall disenfranchisement. High optimism may actually distort the reality of Black elders, who are disproportionately affected by chronic disease and premature mortality (Orsi, Margellos-Anast, \& Whitman, 2010). Because "a sense of personal vulnerability has to be instilled before prevention can be set in gear" (Schwarzer, 1994, p. 164), Blacks' realistic perspective of vulnerability may facilitate active coping (Soler-Vila et al., 2005) and concrete planning. This realism may also override negative beliefs about 
planning. Other studies suggest that defensive pessimism is more pronounced among Black than White college students (Burke, Joyner, Czech, \& Wilson, 2000; Mayo \& Christenfeld, 1999; Norem, 2008), lending further support that less optimism may be a healthy adaptation to difficult circumstances. Although some authors report that resilience is positively correlated with optimism among other Black older adults (Baldwin, Jackson, Okoh, \& Cannon, 2011), more active engagement in planning among less optimistic Blacks might reflect resilience in the face of adversity for our sample. Given the small sample and confounding of sample and race in these two studies, our findings should be considered exploratory. Future research is needed to disentangle the meaning of optimism in the face of adverse circumstances for Blacks.

In addition, Blacks reported higher levels of avoidance than Whites in the community sample. But because race was not an independent multivariate predictor of PFC, the difference was not apparent in the exploratory analysis (though it did appear in the betweensubjects effects, $F=3.922, d f=1, p<.05$ ). It was clear in the analysis of separate samples. Contemplating a future with limited access to resources may be stressful (Sörensen \& Zarit, 1996; Sörensen, 1998) and therefore lead to greater avoidance. For Blacks, concerns stemming from historical segregation and oppression in the medical field (Crawley et al., 2000), as well as reduced access to resources may also contribute to higher avoidance of considering future care needs (Pinquart, Sörensen, \& Davey, 2003). However, because Blacks may be more likely to feel that their needs will be met by the community or church or by trusted family members - higher avoidance of future care planning, on the one hand, may be balanced by greater concrete planning on the other, as their plans may simply rely on family or community, rather than medical facilities (Con, 2008).

Limitations-Our novel findings must be interpreted within the context of study limitations, including the use of two relatively small samples in which confounding by measured and unmeasured variables is possible. We were unable to eliminate the sample effect by including race and a variety of other distinguishing characteristics, leaving unresolved the question of what drives the sample differences. Race certainly played a role and may act as a proxy for different levels or patterns of social support, which could influence both the process and content of future planning.

Because of our cross-sectional design, causality cannot be inferred. For example, it would not be unreasonable to infer the opposite direction of causality: that more future care planning would predict lower optimism, since considering future frailty may increase awareness of potential unpleasant future events. Similarly, a third variable might predict both. However, if the LOT-R indeed assesses trait-like rather than state characteristics, then optimism is more likely a predictor than an outcome. Future research might attempt to differentiate between dispositional, or trait-like, optimism, and state-like or situational optimism, as these two constructs may have differential effects on health planning and outcomes (Scheier \& Carver, 1985; Schwarzer, Diehl, \& Schmitz, 1999).

Another limitation is the age of our data. With the passage of the Affordable Care Act and other health policy innovations, the climate for PFC might have changed since these data were collected. Since our data collection period there have been several public policy 
attempts to encourage future planning in the United States. For example, "Own Your Future" was a recent six-state campaign to influence social pressure to plan and consider long-term care insurance and order a long-term care planning kit (Administration on Aging, 2009; McCay et al., 2006). The project involved state-based direct mail campaigns supported by each participating state's governor, targeting households with members between the ages of 45 to 70. Campaign materials included a Long-Term Care Planning Kit and state-specific information and resources. The point of this campaign was to change the social views on planning for future care; however, the effectiveness of these programs was modest with regard to ordering the planning kit and obtaining long-term care insurance. Despite these efforts, most older still adults have a "false sense of security and entitlement" (Moses, 2011) and face substantial financial risk and high demand on their decision-making ability to deal with health and long-term care (Spillman, 2012).

Finally, because our study involved secondary data analysis, the distribution of ethnicity, income, and education across the two data sets was not random. Self-selection bias may have differed between our recruitment sites, as did our method of survey administration. Despite exclusion criteria for both samples that ensured no older adult with severe cognitive impairment participated, we were unable to statistically control for executive function, including self-initiation, problem-solving and self-monitoring which may affect planning for future care needs (Burke, Zencius, Wesolowski, \& Doubleday, 1991). Thus, our findings require replication, using a more purposeful sampling design and prospective assessment strategy, to substantiate potential race/ethnic disparities in planning for future care, and the role of optimism in such health processes (Fiscella, Franks, Gold, \& Clancy, 2000; Weinick, Zuvekas, \& Cohen, 2000).

Implications-Even though PFC can be very useful in the context of care transitions and may have protective effects for older adults future well-being (Maloney et al., 1996; Pinquart \& Sörensen, 2002a; Pinquart \& Sörensen, 2002b; Reinardy, 1992; Sörensen et al., 2012b; Steele, Pinquart, \& Sörensen, 2003), too few older adults initiate discussion of future care planning with relatives or physicians (Hoffman et al., 1997). Our study provides insight into the interplay of individual beliefs (optimism, beliefs about the usefulness of planning) and cultural factors (race) that serve as either barriers or facilitators of PFC. Schwarzer and colleagues (Schwarzer et al., 2007) describe the type of optimism that leads positive health behaviors and, thus, better health outcomes as "functional" or "adaptive" optimism, whereas optimism that discounts potential health threats and leads to is labeled "defensive" or "unrealistic" optimism (Weinstein, 1987). From a public health perspective, addressing overly optimistic attitudes may be a first step to reducing barriers to care planning, since many older adults have serious misconceptions about the financing and availability of longterm care. In light of recent evidence regarding the modifiability of older adults' positivity bias (Knight et al., 2007), increases in future planning may be achieved by encouraging preemptive planning for future care, including (1) systematic assessment of the patients' stage of and readiness for planning, (2) identification of both motivating factors (such as protecting caregivers from excessive stress) and (3) uncovering relevant barriers to PFC (Pinquart, Sörensen, \& Peak, 2004), possibly making use of cognitive-behavioral therapeutic techniques, such as goal-setting, cognitive restructuring, and challenging attributions. 
Indeed, programs have been developed to modify future planning among older adults (Bode \& de Ridder, 2007; Bode, de Ridder, Kuijer, \& Bensing, 2007; Cheung, Kwan, \& Ng, 2006; Kane, Boston, \& Chilvers, 2007; McCay et al., 2006), based on proactive coping and problem solving models (Arean et al., 2010; Bode et al., 2007; Mynors-Wallis, 1996).

Importantly, our results suggest that any efforts to promote future care planning should incorporate cultural elements. We found that Blacks are more likely to avoid future care planning than Whites, supporting research that suggests Blacks may be less likely than Whites to communicate their future care and end-of-life preferences to physicians (McKinley et al., 1996; Phipps et al., 2003). Further, with increasing optimism, Blacks may be less likely to make concrete plans for the future. Therefore, interventions targeting overly optimistic African-Americans are most likely to address this avoidance, perhaps by providing information about common disability patterns among older Blacks combined with information about community-based sources of assistance, and via culturally relevant channels of communication such as familial and church-based networks (Lumpkins, Coffey, Daley, \& Greiner, 2013; Odulana et al., 2013).

In conclusion, we present preliminary evidence that high levels of optimism may inhibit future care planning among Blacks, but not among Whites. Specifically, our data suggest that concrete planning is negatively related to optimism among Black older adults. In addition, beliefs about future care planning may be an important area of interventions, as many older adults believe that they have little control over future quality of life. Prospective research is necessary to determine how alteration of optimistic beliefs might affect health care decision making, including future care planning, and how such effects may differ by ethnicity. Public health messaging, and clinicians working with patients making health decisions, must strike a balance between encouragement of optimism and ensuring that a patients' future perspective on care needs is based on diagnostic and prognostic accuracy.

\section{References}

Achat H, Kawachi I, Spiro A 3rd, DeMolles DA, Sparrow D. Optimism and depression as predictors of physical and mental health functioning: The normative aging study. Annals of Behavioral Medicine. 2000; 22:127-130. [PubMed: 10962705]

Administration on Aging. National Clearinghouse For Long-Term Care Information: Own your future. 2009. Retrieved from http://www.longtermcare.gov/LTC/Main_Site/Planning_LTC/Campaign/ index.aspx

Arean PA, Raue P, Mackin RS, Kanellopoulos D, McCulloch C, Alexopoulos GS. Problem-solving therapy and supportive therapy in older adults with major depression and executive dysfunction. American Journal of Psychiatry. 2010; 167:1391-1402. [PubMed: 20516155]

Aspinwall, LG. Where planning meets coping: Proactive coping and the detection and management of potential stressors. In: Friedman, SL.; Scholnick, EK., editors. The developmental psychology of planning: Why, how, and when do we plan?. Erlbaum; Mahwah, NJ: 1997. p. 285-319.

Aspinwall LG, Taylor S. A stitch in time: Self-regulation and proactive coping. Psychological Bulletin. 1997; 121:417-436. [PubMed: 9136643]

Baldwin DR, Jackson D, Okoh I, Cannon RL. Resiliency and optimism: An African-American senior citizen's perspective. Journal of Black Psychology. 2011; 37:24-41.

Barnoy S, Bar-Tal Y, Treister L. Effect of unrealistic optimism, perceived control over disease, and experience with female cancer on behavioral intentions of Israeli women to undergo screening tests. Cancer Nursing. 2003; 26:363-369. [PubMed: 14710797] 
Benyamini Y, Idler EL, Leventhal H, Leventhal EA. Positive affect and function as influences on selfassessments of health: Expanding our view beyond illness and disability. Journals of Gerontology: Series B: Psychological Sciences and Social Sciences. 2000; 55B:P107-P116.

Bode C, de Ridder DTD. Investing in the future - Identifying participants in an educational program for middle-aged and older adults. Health Education Research. 2007; 22:473-482. [PubMed: 17018768]

Bode C, de Ridder DTD, Kuijer RG, Bensing JM. Effects of an intervention promoting proactive coping competencies in middle and late adulthood. The Gerontologist. 2007; 47:42-51. [PubMed: 17327539]

Brody BL, Roch-Levecq AC, Gamst AC, Maclean K, Kaplan RM, Brown SI. Self-management of age-related macular degeneration and quality of life: A randomized controlled trial. Archives of Ophthalmology. 2002; 120:1477-1483. [PubMed: 12427060]

Burke KL, Joyner AB, Czech DR, Wilson MJ. An investigation of concurrent validity between two optimism/pessimism questionnaires: The Life Orientation Test-Revised and the Optimism/ Pessimism Scale. Current Psychology. 2000; 19:129-136.

Burke W, Zencius A, Wesolowski M, Doubleday F. Improving executive function disorders in braininjured clients. Brain Injury. 1991; 5:241-252. [PubMed: 1933075]

Caron CD, Ducharme F, Griffith J. Deciding on institutionalization for a relative with dementia: The most difficult decision for caregivers. Canadian Journal on Aging. 2006; 25:193-205. [PubMed: 16821201]

Carstensen LL. The influence of a sense of time on human development. Science. 2006; 312(5782): 1913-1915. [PubMed: 16809530]

Carstensen LL, Fung HH, Charles ST. Socioemotional selectivity theory and the regulation of emotion in the second half of life. Motivation and Emotion. 2003; 27:103-123.

Chang EC. Dispositional optimism and primary and secondary appraisal of a stressor: Controlling for confounding influences and relations to coping and psychological and physical adjustment. Journal of Personality and Social Psychology. 1998; 74:1109-1120.

Cheung C, Kwan AY, Ng SH. Impacts of filial piety on preference for kinship versus public care. Journal of Community Psychology. 2006; 34:617-634.

Con, A. Cross-cultural considerations in promoting advance care planning in Canada. Secretariat on Palliative and End-of-Life Care, Primary and Continuing Health Care Division; Vancouver: 2008.

Congdon JG, Magilvy JK. Hallmarks of quality: Generating knowledge to assist consumers of longterm care. Communicating Nursing Research. 2004; 37:37-42. [PubMed: 15320537]

Conwell Y, Forbes NT, Cox C, Caine ED. Validation of a measure of physical illness burden at autopsy: The cumulative illness rating scale. Journal of the American Geriatrics Society. 1993; 41:38-41. [PubMed: 8418120]

Coyne JC, Fechner-Bates S, Schwenk TL. Prevalence, nature, and comorbidity of depressive disorders in primary care. General Hospital Psychiatry. 1994; 16:267-276. [PubMed: 7926703]

Crawley L, Payne R, Bolden J, Payne T, Washington P, Williams S. Palliative and end-of-life care in the African-American community. The Journal of the American Medical Association. 2000; 284:2518-2521.

Daaleman TP, VandeCreek L. Placing religion and spirituality in end-of-life care. The Journal of the American Medical Association. 2000; 284:2514-2517.

Delgadillo L, Sörensen S, Costner DC. An exploratory study of factors related to preparation for future care among older Latinos in Utah. Journal of Family and Economic Issues. 2004; 25:51-79.

Duke J, Leventhal H, Brownlee S, Leventhal EA. Giving up and replacing activities in response to illness. The Journals of Gerontology Series B: Psychological Sciences and Social Sciences. 2002; 57:P367-P376.

Ersek M, Kagawa-Singer M, Barnes D, Blackhall L, Koenig BA. Multicultural considerations in the use of advance directives. Oncology Nursing Forum. 1998; 25:1683-1684. [PubMed: 9826836]

Escarce JJ, Epstein KR, Colby DC, Schwartz JS. Racial differences in the elderly's use of medical procedures and diagnostic tests. American Journal of Public Health. 1993; 83:948-954. [PubMed: $8328615]$ 
Ferreira VM, Sherman AM. The relationship of optimism, pain and social support to well-being in older adults with osteoarthritis. Aging and Mental Health. 2007; 11:89-98. [PubMed: 17164163]

Fiksenbaum LM, Greenglass ER, Eaton J. Perceived social support, hassles, and coping among the elderly. Journal of Applied Gerontology. 2006; 25:17-30.

Fiscella K, Franks P, Gold MR, Clancy CM. Inequality in quality: Addressing socioeconomic and ethnic disparities in health care. The Journal of the American Medical Association. 2000; 283:2579-2584.

Forbes S, Hoffart N. Elders' decision making regarding the use of long-term care services: A precarious balance. Qualitative Health Research. 1998; 8:736-750. [PubMed: 10558344]

Fortin M, Bravo G, Hudon C, Vanasse A, Lapointe L. Prevalence of multimorbidity among adults seen in family practice. The Annals of Family Medicine. 2005; 3:223-228.

Hoffman JC, Wenger N, Davis RD, Teno J, Connors AF, Desbiens N, Phillips RS. Patient preferences for communication with physicians about end of life decisions. Annals of Internal Medicine. 1997; 127:1-12. doi 10.7326/0003-4819-127-1-199707010-00001. [PubMed: 9214246]

Howlett E, Kees J, Kemp E. The role of self-regulation, future orientation, and financial knowledge in long-term financial decisions. Journal of Consumer Affairs. 2008; 42:223-242.

Ironson G, Balbin E, Stuetzle R, Fletcher MA, O’Cleirigh C, Laurenceau JP, Solomon G. Dispositional optimism and the mechanisms by which it predicts slower disease progression in HIV: Proactive behavior, avoidant coping, and depression. International Journal of Behavioral Medicine. 2005; 12:86-97. [PubMed: 15901217]

Jenkins C, Lapelle N, Zapka JG, Kurent JE. End-of-life care and African-Americans: Voices from the community. Journal of Palliative Medicine. 2005; 8:585-592. [PubMed: 15992200]

Jones DJ, O'Connell C, Gound M, Heller L, Forehand R. Predictors of self-reported physical symptoms in low-income, innercity African-American women: The role of optimism, depressive symptoms, and chronic illness. Psychology of Women Quarterly. 2004; 28:112-121.

Jones PS, Lee JW, Zhang XE. Clarifying and measuring filial concepts across five cultural groups. Research in Nursing \& Health. 2011; 34:310-326. [PubMed: 21618557]

Kahana E, Kahana B, Zhang J. Motivational antecedents of preventive proactivity in late life: Linking future orientation and exercise. Motivation and Emotion. 2005; 29:443-464.

Kane RL, Boston K, Chilvers M. Helping people make better long-term-care decisions. The Gerontologist. 2007; 47:244-247. [PubMed: 17440129]

Karademas EC. Self-efficacy, social support and well-being: The mediating role of optimism. Personality and Individual Differences. 2006; 40:1281-1290.

Klein, W.; Zajac, L. Imagining a rosy future: The psychology of optimism. In: Markman, KD.; Klein, WMP.; Suhr, JA., editors. Handbook of imagination and mental simulation. CRC Press; Boca Raton, FL: 2009. p. 313-330.

Klein WMP, Stefanek ME. Cancer risk elicitation and communication: Lessons from the psychology of risk perception. CA: A Cancer Journal for Clinicians. 2007; 57:147-167. [PubMed: 17507441]

Knight M, Seymour TL, Gaunt JT, Baker C, Nesmith K, Mather M. Aging and goal-directed emotional attention: Distraction reverses emotional biases. Emotion. 2007; 7:705-714. [PubMed: 18039037]

Kubzansky LD, Wright RJ, Cohen S, Weiss S, Rosner B, Sparrow D. Breathing easy: A prospective study of optimism and pulmonary function in the normative aging study. Annals of Behavioral Medicine. 2002; 24:345-353. [PubMed: 12434946]

Lachman ME, Howland J, Tennstedt S, Jette A, Assmann S, Peterson EW. Fear of falling and activity restriction: The survey of activities and fear of falling in the elderly (SAFE). The Journals of Gerontology Series B: Psychological Sciences and Social Sciences. 1998; 53:P43-P50.

Lang FR, Weiss D, Gerstorf D, Wagner GG. Forecasting life satisfaction across adulthood: Benefits of seeing a dark future? Psychology and Aging. 2013; 28:249. [PubMed: 23421319]

Lawton MP, Brody EM. Assessment of older people: Self-maintaining and instrumental activities of daily living. The Gerontologist. 1969; 9:179-186. [PubMed: 5349366]

Lazarus, RS. Emotion and adaptation. Oxford University Press; New York: 1991. 
Lillie-Blanton M, Brodie M, Rowland D, Altman D, McIntosh M. Race, ethnicity, and the health care system: Public perceptions and experiences. Medical Care Research and Review. 2000; 57(4 suppl):218-235. [PubMed: 11092164]

Linn BS, Linn MW, Gurel L. Cumulative illness rating scale. Journal of the American Geriatrics Society. 1968; 16:622-626. [PubMed: 5646906]

Liu L, Tinker A. Factors associated with nursing home entry for older people in taiwan, republic of china. Journal of Interprofessional Care. 2001; 15:245-255. [PubMed: 11705233]

Lowenstein A, Katz R, GurYaish N. Reciprocity in parent-child exchange and life satisfaction among the elderly: A cross-national perspective. Journal of Social Issues. 2007; 63:865-883.

Lumpkins CY, Coffey CR, Daley CM, Greiner KA. Employing the church as a marketer of cancer prevention: A look at a health promotion project aimed to reduce colorectal cancer among AfricanAmericans in the Midwest. Family \& Community Health. 2013; 36:215-223. [PubMed: 23718957]

Maloney SK, Finn J, Bloom D, Andresen J. Personal decision making styles and long-term care choices. Health Care Financing Review. 1996; 18:141-156. [PubMed: 10165028]

Matsumura S, Bito S, Liu H, Kahn K, Fukuhara S, Kagawa-Singer M, Wenger N. Acculturation of attitudes toward end-of-life care. Journal of General Internal Medicine. 2002; 17:531-539. [PubMed: 12133143]

Mayo MW, Christenfeld N. Gender, race, and performance expectations of college students. Journal of Multicultural Counseling and Development. 1999; 27:93-104.

McCay, H.; Long Term Care Group Inc.. LifePlans Inc.. Final report on the Own Your Future consumer survey. 2006. Retrieved from http://aspe.dhhs.gov/daltcp/reports/2006/OYFsurvey.pdf/ Phase\%201\%20Consumer\%20Survey.pdf

McKinley ED, Evans AT, Danis M. Differences in end-of-life decision making among black and white ambulatory cancer patients. Journal of General Internal Medicine. 1996; 11:651-656. [PubMed: 9120650]

Miles S, Scaife V. Optimistic bias and food. Nutrition Research Reviews. 2003; 16:3-20. [PubMed: 19079933]

Moses, SA. MediCal long-term care: Safety net or hammock?. 2011. http://www.centerltc.com/pubs/ Medi-Cal-LTC--Safety_Net_or_Hammock.pdf

Mynors-Wallis L. Problem-solving treatment: Evidence for effectiveness and feasibility in primary care. International Journal of Psychiatry in Medicine. 1996; 26:249-262. [PubMed: 8976466]

Norem JK. Defensive pessimism, anxiety, and the complexity of evaluating self-regulation. Social and Personality Psychology Compass. 2008; 2:121-134.

Odulana AA, Kim MM, Isler MR, Green MA, Taylor YJ, Howard DL, Corbie-Smith G. Examining characteristics of congregation members willing to attend health promotion in African-American churches. Health Promotion Practice. 2013; 15:125-133. [PubMed: 23493800]

Orsi JM, Margellos-Anast H, Whitman S. Black-white health disparities in the united states and chicago: A 15-year progress analysis. American Journal of Public Health. 2010; 100:349-356. [PubMed: 20019299]

Ostir GV, Markides KS, Peek MK, Goodwin JS. The association between emotional well-being and the incidence of stroke in older adults. Psychosomatic Medicine. 2001; 63:210-215. [PubMed: 11292267]

Parker MG, Thorslund M. Health trends in the elderly population: Getting better and getting worse. The Gerontologist. 2007; 47:150-158. [PubMed: 17440120]

Phipps E, True G, Harris D, Chong U, Tester W, Chavin SI, Braitman LE. Approaching the end of life: Attitudes, preferences, and behaviors of African-American and white patients and their family caregivers. Journal of Clinical Oncology. 2003; 21:549-554. [PubMed: 12560448]

Pinquart M, Sörensen S. Vorausplanen oder nicht daran denken - Auseinandersetzung von Senioren mit dem Risiko, künftig Pflege zu benötigen. [To plan ahead or to ignore: Seniors' consideration of the risk of their needing future care]. Symposium Medical. 2002a; 13:76-86.

Pinquart M, Sörensen S. Psychological outcomes of preparation for future care needs. Journal of Applied Gerontology. 2002b; 21:452-470. 
Pinquart M, Sörensen S, Davey A. National and regional differences in preparation for future care needs: A comparison of the United States and Germany. Journal of Cross-Cultural Gerontology. 2003; 18:53, 78. [PubMed: 14617958]

Pinquart M, Sörensen S, Peak T. Helping older adults and their families develop and implement care plans. Journal of Gerontological Social Work. 2004; 43(4):3-23.

Prenda KM, Lachman ME. Planning for the future: A life management strategy for increasing control and life satisfaction in adulthood. Psychology and Aging. 2001; 16:206-216. [PubMed: 11405309]

Radcliffe NM, Klein WM. Dispositional, unrealistic, and comparative optimism: Differential relations with the knowledge and processing of risk information and beliefs about personal risk. Personality and Social Psychology Bulletin. 2002; 28:836-846.

Rakowski W, Clark NM. Future outlook, caregiving, and care-receiving in the family context. The Gerontologist. 1985; 25:618-623. [PubMed: 4085876]

Rasmussen HN, Scheier MF, Greenhouse JB. Optimism and physical health: A meta-analytic review. Annals of Behavioral Medicine. 2009; 37:239-256. [PubMed: 19711142]

Rasmussen HN, Wrosch C, Scheier MF, Carver CS. Self-regulation processes and health: The importance of optimism and goal adjustment. Journal of Personality. 2006; 74:1721-1747. [PubMed: 17083664]

Reinardy JR. Decisional control in moving to a nursing home: Postadmission adjustment and wellbeing. The Gerontologist. 1992; 32:96-103. [PubMed: 1740262]

Robinson-Whelen S, Kim C, MacCallum RC, Kiecolt-Glaser JK. Distinguishing optimism from pessimism in older adults: Is it more important to be optimistic or not to be pessimistic? Journal of Personality \& Social Psychology. 1997; 73:1345-1353. [PubMed: 9418282]

Royall DR, Cabello M, Polk MJ. Executive dyscontrol: An important factor affecting the level of care received by older retirees. Journal of the American Geriatrics Society. 1998; 49:1519-1524. [PubMed: 9848812]

Saab PG, Llabre MM, Schneiderman N, Hurwitz BE, McDonald PG, Evans J, Klein B. Influence of ethnicity and gender on cardiovascular responses to active coping and inhibitory-passive coping challenges. Psychosomatic Medicine. 1997; 59:434-446. [PubMed: 9251164]

Scheier MF, Carver CS, Bridges MW. Distinguishing optimism from neuroticism (and trait anxiety, self-mastery, and self-esteem): A re-evaluation of the life orientation test. Journal of Personality and Social Psychology. 1994; 67:1063-1078. [PubMed: 7815302]

Scheier MF, Carver CS. Optimism, coping, and health: Assessment and implications of generalized outcome expectancies. Health Psychology. 1985; 4:219-247. [PubMed: 4029106]

Schwarzer, R.; Diehl, M.; Schmitz, GS. Self-regulation. 1999. Retrieved from http://userpage.fuberlin.de/ health/selfreg_e.htm

Schwarzer R. Optimism, vulnerability, and self-beliefs as health-related cognitions: A systematic overview. Psychology and Health. 1994; 9:161-180.

Schwarzer R, Schüz B, Ziegelmann JP, Lippke S, Luszczynska A, Scholz U. Adoption and maintenance of four health behaviors: Theory-guided longitudinal studies on dental flossing, seat belt use, dietary behavior, and physical activity. Annals of Behavioral Medicine. 2007; 33:156166. [PubMed: 17447868]

Sears S, Woodward J, Twillman J. What do I have to lose? Effects of a psycho-educational intervention on cancer patient preference for resuscitation. Journal of Behavioral Medicine. 2007; 30:533-544. [PubMed: 17712617]

Smith N, Young A, Lee C. Optimism, health-related hardiness and well-being among older Australian women. Journal of Health Psychology. 2004; 9:741-752. [PubMed: 15367753]

Soler-Vila H, Kasl SV, Jones BA. Prognostic significance of psychosocial factors in African-American and White breast cancer patients. Cancer. 2003; 98:1299-1308. [PubMed: 12973855]

Sörensen S, Mak W, Chapman B, Duberstein PR, Lyness JM. The relationship of preparation for future care to depression and anxiety in older primary care patients at 2-year follow-up. The American Journal of Geriatric Psychiatry. 2012a; 20:887-894. [PubMed: 21952122]

Sörensen S, Pinquart M. Developing a measure of older adults' preparation for future care needs. International Journal of Aging and Human Development. 2001a; 53:137-165. [PubMed: 11758723] 
Sörensen S, Zarit S. Preparation for caregiving: A study of multigeneration families. The International Journal of Aging and Human Development. 1996; 42:43-63.

Sörensen S. Predictors of anticipating caregiving in multigeneration families: An exploratory study. Journal of Applied Gerontology. 1998; 17:499-520.

Sörensen S, Mak W, Chapman B, Duberstein P, Lyness J. The relationship of preparation for future care to depression and anxiety in older primary care patients at 2-year follow-up. Am Journal of Geriatric Psychiatry. 2012b; 20:887-894.

Sörensen S, Pinquart M. Vulnerability and access to resources as predictors of preparation for future care needs in the elderly. Journal of Aging and Health. 2001b; 12:275-300.

Sörensen S, Duberstein PR, Chapman B, Lyness JM, Pinquart M. How are personality traits related to preparation for future care needs in older adults? The Journals of Gerontology: Series B: Psychological Sciences and Social Sciences. 2008; 63B:P328-P336.

Sörensen S, Pinquart M. Preparation for future care needs by West and East German older adults. Journals of Gerontology: Series B: Psychological Sciences and Social Sciences. 2000; 55B:S357S367.

Spillman, B. Financial preparedness for long-term care needs in old age. In: Lamdin, DJ., editor. Consumer knowledge and financial decisions: Life-span perspectives. Springer-Verlag; New York: 2012. p. 239-253.

Steele M, Pinquart M, Sörensen S. Preparation dimensions and styles in long term care. Clinical Gerontologist. 2003; 26(3/4):105-122.

Tabachnick, BG.; Fidell, LS. Computer-assisted research design and analysis. Allyn and Bacon; Boston, MA: 2001.

Taylor SE, Armor DA. Positive illusions and coping with adversity. Journal of Personality. 1996; 64:873-898. [PubMed: 8956516]

Taylor SE, Brown JD. Illusion and well-being: A social psychological perspective on mental health. Psychological Bulletin. 1988; 103:193-210. [PubMed: 3283814]

Travis LA, Lyness JM, Shields CG, King DA, Cox C. Social support, depression, and functional disability in older adult primary-care patients. American Journal of Geriatric Psychiatry. 2004; 12:265-271. [PubMed: 15126227]

Travis SS, McAuley WJ. Searches for a nursing home: Personal and situational factors. Journal of Applied Gerontology. 1998; 17:352-370.

Walz HS, Mitchell TE. Adult children and their parents' expectations of future elder care needs. Journal of Aging and Health. 2007; 19:482-499. [PubMed: 17496246]

Weinick RM, Zuvekas SH, Cohen JW. Racial and ethnic differences in access to and use of health care services, 1977 to 1996. Medical Care Research and Review. 2000; 57(suppl. 1):36-54. [PubMed: 11092157]

Weinstein N. Unrealistic optimism about susceptibility to health problems: Conclusions from a community-wide sample. Journal of Behavioral Medicine. 1987; 10:481-500. [PubMed: 3430590]

Wilcox VL, Kasl SV, Idler EL. Self-rated health and physical disability in elderly survivors of a major medical event. The Journals of Gerontology Series B: Psychological Sciences and Social Sciences. 1996; 51:S96-S104. 


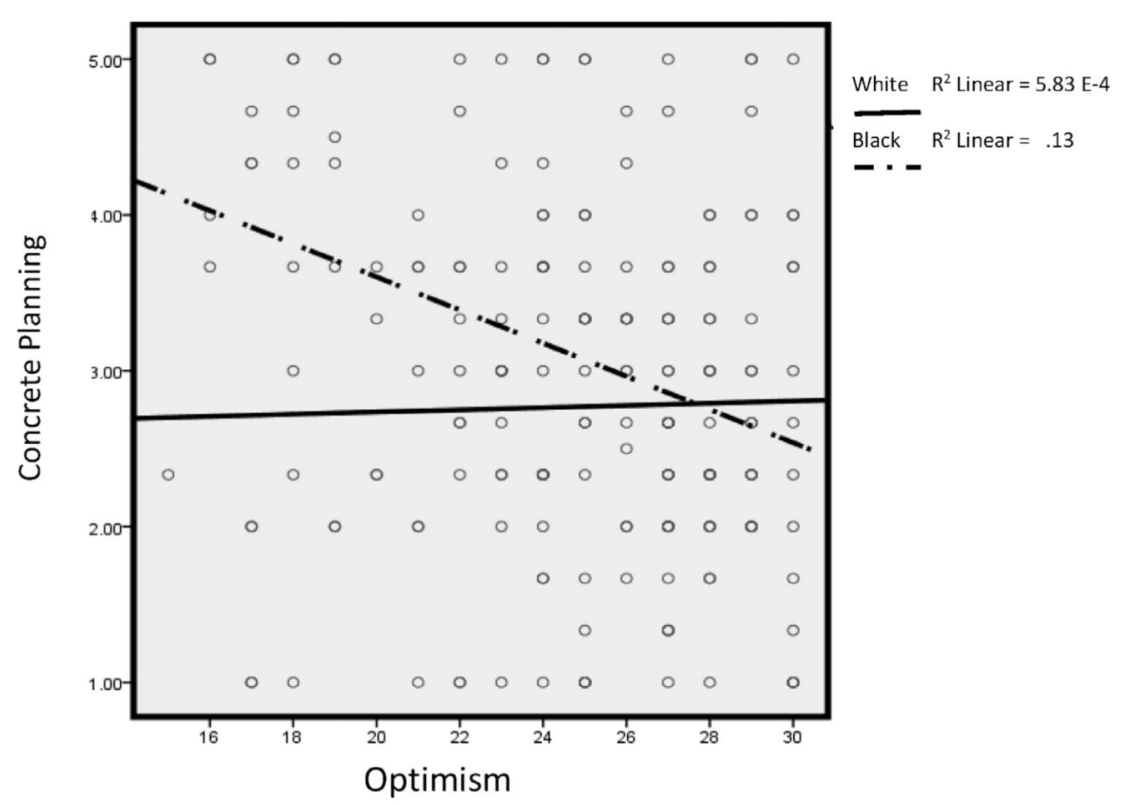

Figure 1.

Moderating effect of race on relationship between concrete planning and optimism. 
Table 1

Descriptives and frequencies of demographic characteristics and study variables

\begin{tabular}{|c|c|c|c|c|}
\hline Variable & $\begin{array}{l}\text { Primary care sample }(1) \\
\text { Mean }(S D), \text { median/\% } \\
[N]=67]\end{array}$ & $\begin{array}{l}\text { Community sample }(2) \\
\text { Mean }(S D), \text { median } / \% \\
{[N=130]}\end{array}$ & $\begin{array}{l}\text { Study samples compared } \\
T \text { or } \chi^{2} \text { (italics) }\end{array}$ & $d f$ \\
\hline $\mathrm{Age}^{* *}$ & $74.36(5.29)(65-85)$ & 71.44 (7.85) Range 59-89 & 3.08 & 194 \\
\hline Education $^{* * *}$ & $15.09(2.02)$ & $11.49(3.58)$ & 8.64 & 178 \\
\hline Income $^{* *}$ (median category) & $\$ 50,000-\$ 70,000$ & $\$ 10,000$ to $\$ 30,000$ & 42.5 & 7 \\
\hline \multicolumn{5}{|l|}{ Race/Ethnicity ${ }^{* * *}$} \\
\hline Black & $1.5 \%$ & $70.0 \%$ & 87.5 & 3 \\
\hline White & $97.0 \%$ & $28.5 \%$ & & \\
\hline Asian & $1.5 \%$ & $0.0 \%$ & & \\
\hline Biracial & $0.0 \%$ & $1.5 \%$ & & \\
\hline Gender: Women & $59.7 \%$ & $59.7 \%$ & .00 & 1 \\
\hline \multicolumn{5}{|l|}{ Marital status } \\
\hline Married/living with partner & $47.8 \%$ & $27.7 \%$ & 18.6 & 4 \\
\hline Widowed & $34.3 \%$ & $26.2 \%$ & & \\
\hline Divorced & $10.4 \%$ & $26.2 \%$ & & \\
\hline Never married & $6.0 \%$ & $19.2 \%$ & & \\
\hline Other & $1.5 \%$ & $.8 \%$ & & \\
\hline Functional limitations (raw scores) & $\begin{array}{l}2.08(3.13) \\
\text { possible range } 0-42\end{array}$ & $\begin{array}{l}14.78(3.67) \\
\text { possible range 13-39 }\end{array}$ & & \\
\hline Functional limitations ( $z$-score range $-.76-6.32$ ) & $-.11(.91)$ & $.00(1.00)$ & -.76 & 194 \\
\hline Medical burden (raw scores) range & $\begin{array}{l}7.42(2.69) \\
\text { possible range } 0-39\end{array}$ & $\begin{array}{l}3.33(2.35) \\
\text { possible range } 0-23\end{array}$ & & \\
\hline Medical burden ( $z$-score range $-1.89-3.65)$ & $.01(.98)$ & $-.17(1.03)$ & 1.75 & 191 \\
\hline Optimism $^{* *}($ range $15-30)$ & $25.60(3.55)$ & $24.12(3.86)$ & 2.62 & 195 \\
\hline Awareness $^{* * *}($ range $1-5)$ & $2.84(.85)$ & $3.85(.90)$ & -7.50 & 193 \\
\hline Avoidance (range 1-5) & $2.83(.77)$ & $2.94(1.02)$ & -.83 & 164 \\
\hline Gathering Information $^{* * *}$ (range 1-5) & $2.57(1.04)$ & $3.39(1.16)$ & -4.81 & 192 \\
\hline Decision Making $^{* * *}$ (range 1-5) & $3.17(.95)$ & $3.93(.89)$ & -5.37 & 189 \\
\hline Concrete Planning ${ }^{* * *}$ (range 1-5) & $.48(.93)$ & $3.18(1.17)$ & -4.18 & 192 \\
\hline Belief that Planning Is Not Useful ${ }^{* *}$ (range 1-5) & $2.24(.85)$ & $2.72(1.04)$ & -3.42 & 149 \\
\hline Expect Not to Need Care (range 1-5) & $2.61(.81)$ & $2.69(.67)$ & -.71 & 192 \\
\hline
\end{tabular}

Note.

* $p<.05$,

** $p<.01$,

*** $p<.001$. 


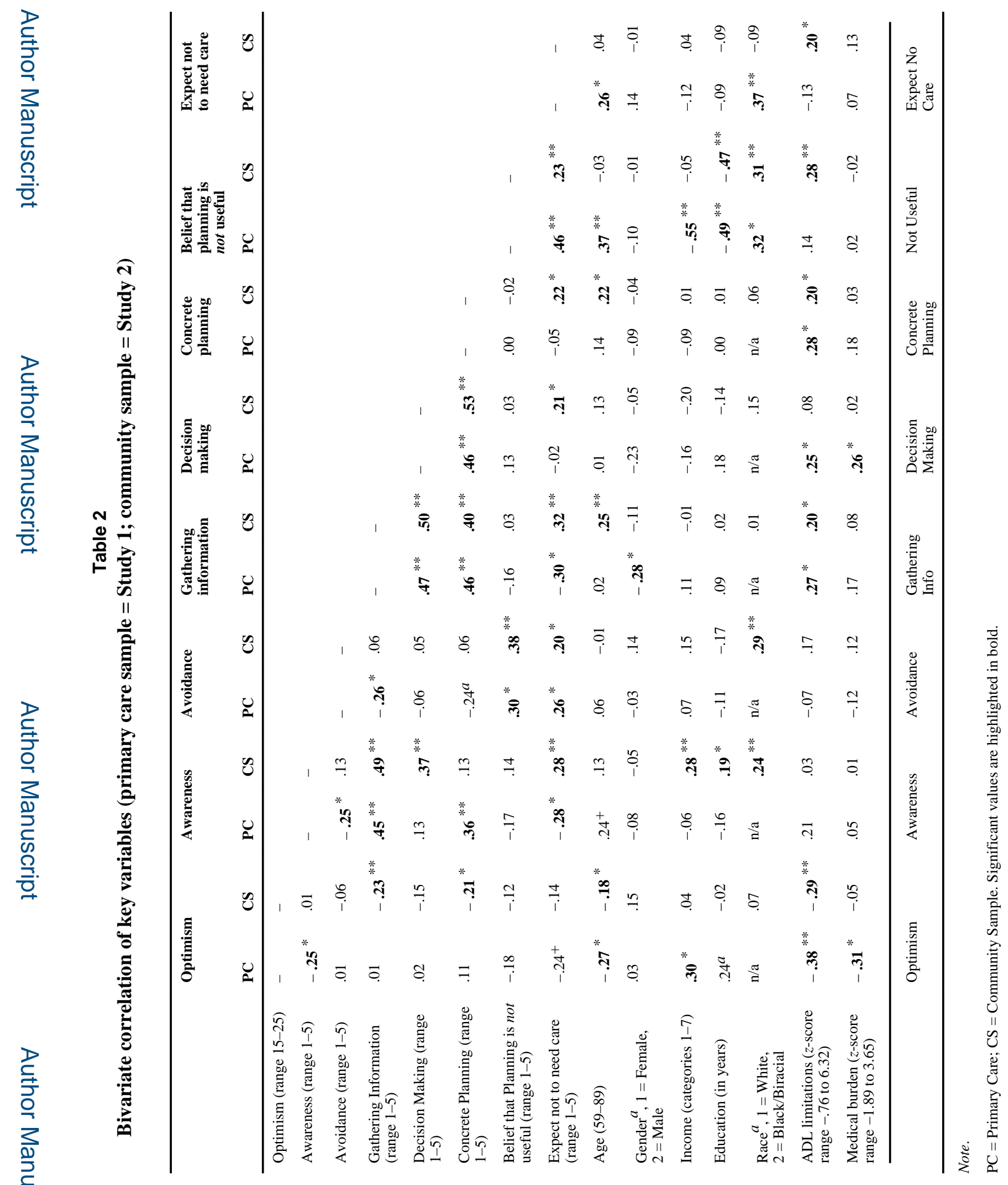

GeroPsych (Bern). Author manuscript; available in PMC 2015 June 02. 


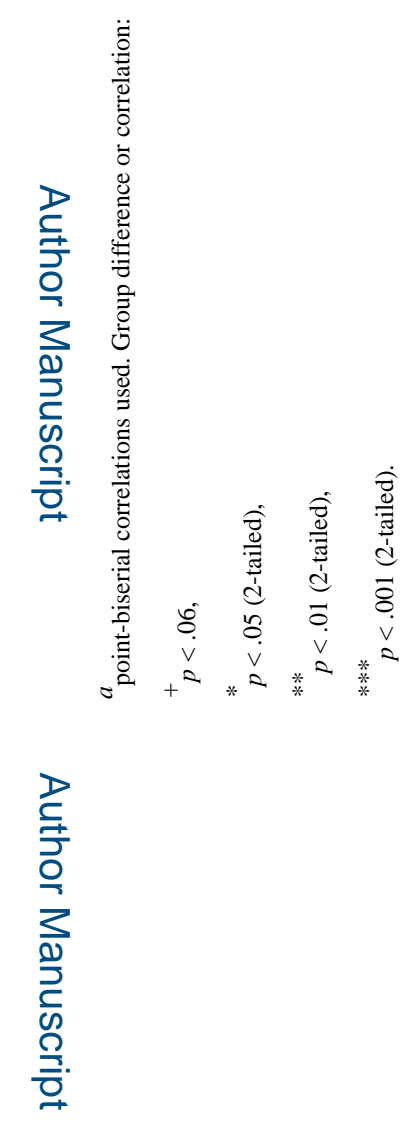

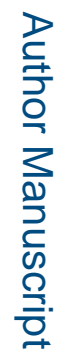

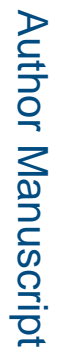

GeroPsych (Bern). Author manuscript; available in PMC 2015 June 02. 


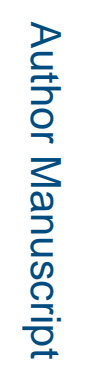

로을

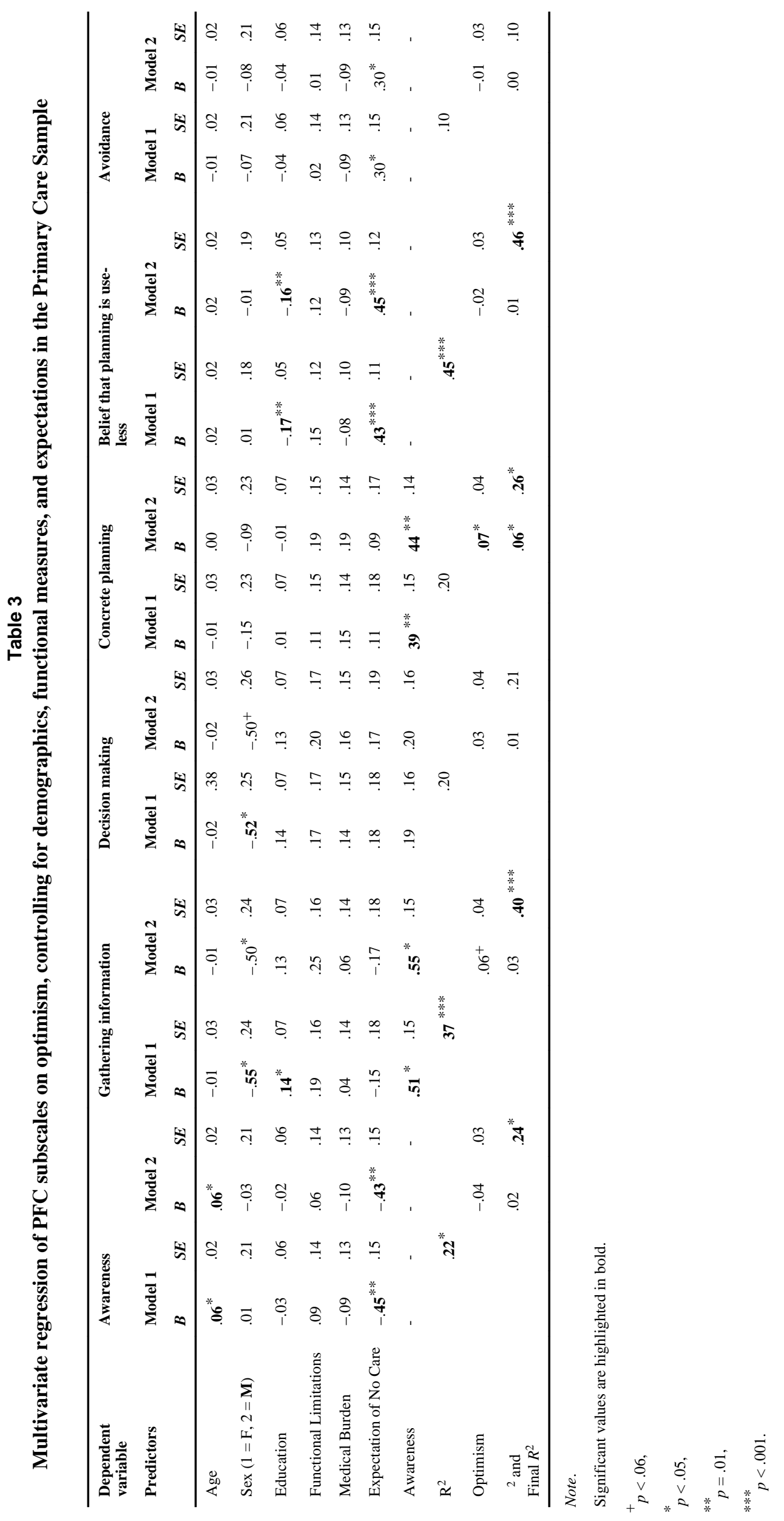




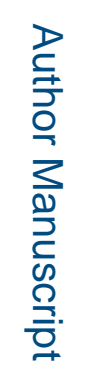

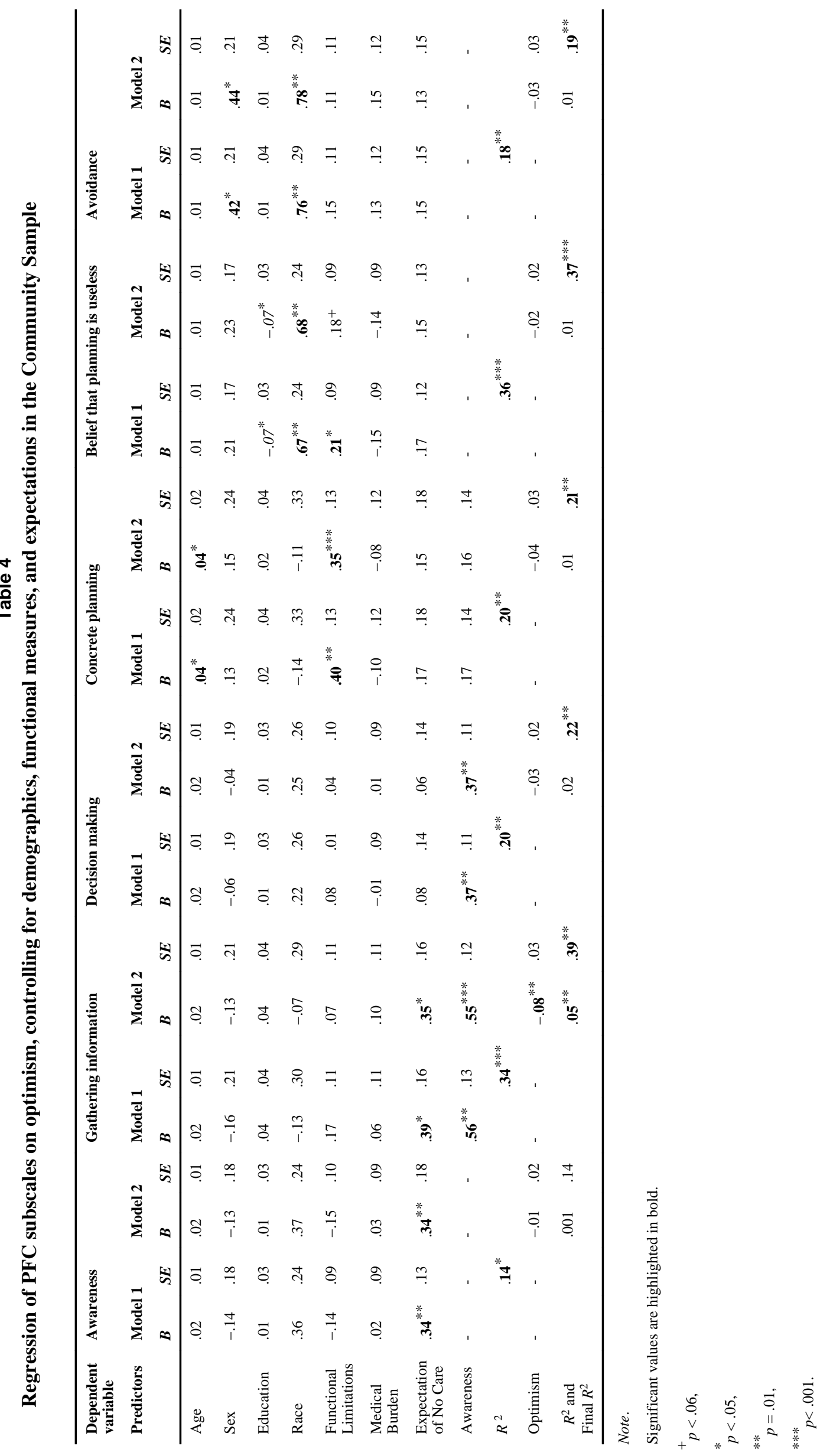

?



GeroPsych (Bern). Author manuscript; available in PMC 2015 June 02. 
Table 5

Multivariate analysis of variance predicting PFC (Awareness, Gathering Information, Decision Making, Concrete Planning, Avoidance)

\begin{tabular}{|c|c|c|c|c|}
\hline Effect & & Value & $\boldsymbol{F}$ & Sig. \\
\hline \multirow[t]{2}{*}{ Intercept } & $\begin{array}{l}\text { Pillai's } \\
\text { trace }\end{array}$ & .095 & $3.08^{*}$ & .011 \\
\hline & Wilks' $\lambda$ & .905 & $3.08^{*}$ & .011 \\
\hline \multirow[t]{2}{*}{ Sample } & $\begin{array}{l}\text { Pillai's } \\
\text { trace }\end{array}$ & .134 & $4.57^{* *}$ & .001 \\
\hline & Wilks' $\lambda$ & .874 & $4.57^{* *}$ & .001 \\
\hline \multirow[t]{2}{*}{ Race (black/other) } & $\begin{array}{l}\text { Pillai's } \\
\text { trace }\end{array}$ & .054 & 1.68 & .142 \\
\hline & Wilks' $\lambda$ & .866 & 1.68 & .142 \\
\hline \multirow[t]{2}{*}{ Sex } & $\begin{array}{l}\text { Pillai's } \\
\text { trace }\end{array}$ & .041 & 1.26 & .287 \\
\hline & Wilks' $\lambda$ & .959 & 1.26 & .287 \\
\hline \multirow[t]{2}{*}{ Age } & $\begin{array}{l}\text { Pillai's } \\
\text { trace }\end{array}$ & .052 & 1.62 & .157 \\
\hline & Wilks' $\lambda$ & .948 & 1.62 & .157 \\
\hline \multirow[t]{2}{*}{ Years of education } & $\begin{array}{l}\text { Pillai's } \\
\text { trace }\end{array}$ & .011 & .33 & .895 \\
\hline & Wilks' $\lambda$ & .989 & .33 & .895 \\
\hline \multirow[t]{2}{*}{$\begin{array}{l}\text { Belief that planning is } \\
\text { not useful }\end{array}$} & $\begin{array}{l}\text { Pillai's } \\
\text { trace }\end{array}$ & .091 & $2.93^{*}$ & .015 \\
\hline & Wilks' $\lambda$ & .909 & $2.93^{*}$ & .015 \\
\hline \multirow[t]{2}{*}{ Expect no future care } & $\begin{array}{l}\text { Pillai's } \\
\text { trace }\end{array}$ & .018 & .52 & .758 \\
\hline & Wilks' $\lambda$ & .982 & .52 & .758 \\
\hline \multirow[t]{2}{*}{ Functional limitations } & $\begin{array}{l}\text { Pillai's } \\
\text { trace }\end{array}$ & .079 & $2.51^{*}$ & .033 \\
\hline & Wilks' $\lambda$ & .921 & $2.51^{*}$ & .033 \\
\hline \multirow[t]{2}{*}{ Medical burden } & $\begin{array}{l}\text { Pillai's } \\
\text { trace }\end{array}$ & .032 & .99 & .429 \\
\hline & Wilks' $\lambda$ & .968 & .99 & .429 \\
\hline \multirow[t]{2}{*}{ Optimism } & $\begin{array}{l}\text { Pillai's } \\
\text { trace }\end{array}$ & .031 & .94 & .458 \\
\hline & Wilks' $\lambda$ & .969 & .94 & .458 \\
\hline \multirow[t]{2}{*}{ Race* optimism } & $\begin{array}{l}\text { Pillai's } \\
\text { trace }\end{array}$ & .078 & $2.50^{*}$ & .033 \\
\hline & Wilks' $\lambda$ & .922 & $2.50^{*}$ & .033 \\
\hline \multirow[t]{2}{*}{ Sample ${ }^{*}$ optimism } & $\begin{array}{l}\text { Pillai's } \\
\text { trace }\end{array}$ & .057 & 1.77 & .123 \\
\hline & Wilks' $\lambda$ & .943 & 1.77 & .123 \\
\hline
\end{tabular}

Note.

In addition to the $F>$ value as the indicator of significance, we use two multivariate measures: Pillai's trace and Wilks' $\lambda$. Pillai's trace is the sum of the variance explained by the calculation of discriminant variables, or the amount of variance in the dependent variable accounted for by the greatest separation of the independent variables. Wilks' $\lambda$ demonstrates how much variance in the dependent variable is accounted for by the independent variable; the smaller the value, the larger the difference between the groups being analyzed. Hypothesis $d f=5$.

GeroPsych (Bern). Author manuscript; available in PMC 2015 June 02. 


$$
\begin{aligned}
& { }_{p}^{*}<.05, \\
& * * \\
& p<.01 ;
\end{aligned}
$$

